\title{
Editorial: In the Light of Mendel
}

The Centennial of Mendel's death was celebrated, in the course of 1984, all over the world. One of these celebrations, and undoubtedly a significant one, took place on the 10th of March in the Vatican City, at the presence of Pope John Paul the Second, who himself commemorated Mendel and praised him as an Augustinian monk and as a scientist, as the founder of genetics.

On this occasion, I had the honor to represent Medical Genetics while the twins were also represented by Father P. Richter, a grand-nephew of Gregor Mendel and himself belonging to the Augustinian Order. The presence of a pair of twins in Mendel's genealogy was not previously known and was learnt with great interest by the numerous Church dignitaries and scientists who were present at the ceremony. The Pope allowed himself to be pictured with a pair of Indian twins in care of the Mendel Institute of Rome and said: "It is with inward joy and with a deep sense of gratitude that I join in the triple homage being paid to Abbott Gregor Mendel: from the Augustinian Order, to which he belonged, from the Pontifical Council for Culture, and from the Mendel Institute of Rome. He was, in fact, at the same time a man of faith, a man of culture, and a man of science. I am grateful to the organizers of this celebration of the Centennial of his death for giving me the opportunity to solemnly underscore this reality".

Father Richter noted that, "To have a famous grand-uncle is a good and honorable thing. And the greater his fame, the warmer its irradiation over the fourth and fifth generation. But then things get complicated if, for that reason, one should expect from Mendel's grand-nephews a genius that is not there. And it is even more complicated to describe adequately, in a short conference, the genius of such a man". And he also noted, in the same address: "In the Mendel family house, an earthenware image of the Trinity has been found with the inscription, 'Thy Will Be Done'. This short sentence, encompassing a whole program of life, must have deeply impressed young Mendel's mind, who was brought up, with his sisters, Veronica and Theresa, in a profoundly Christian environment. And perhaps already then, and certainly favored by the forming principles of his father and of his parish priest, Father Schreiber, did the profound conviction develop in his mind that the forces of nature behave according to a secret harmony, which it is the task of man to discover, for his own sake and his Creator's glory'. 


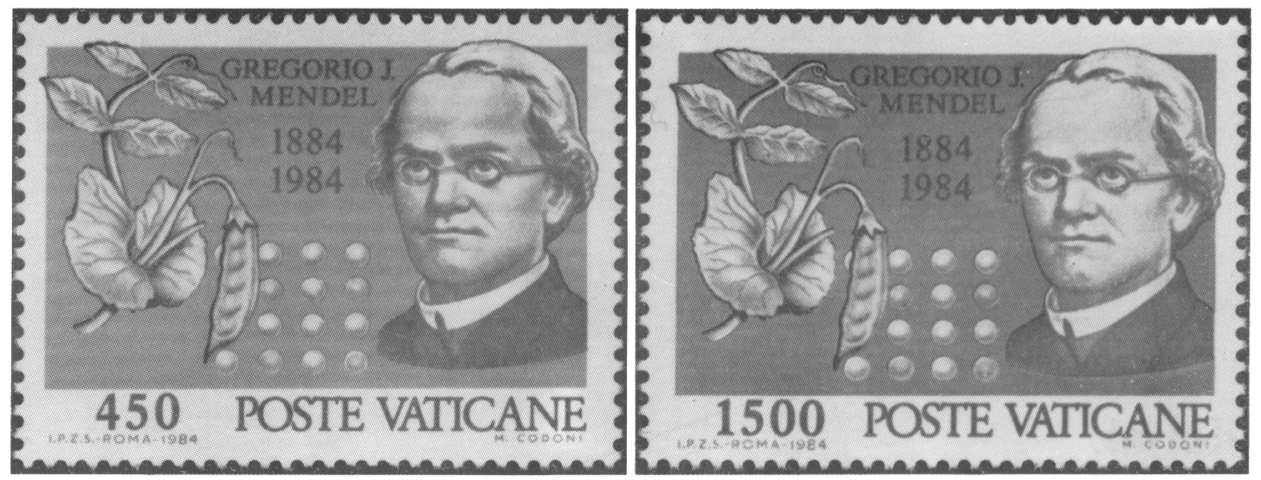

Fig. 1 - Special stamps issued by the Vatican to celebrate the Centennial of Gregor Mendel's death.

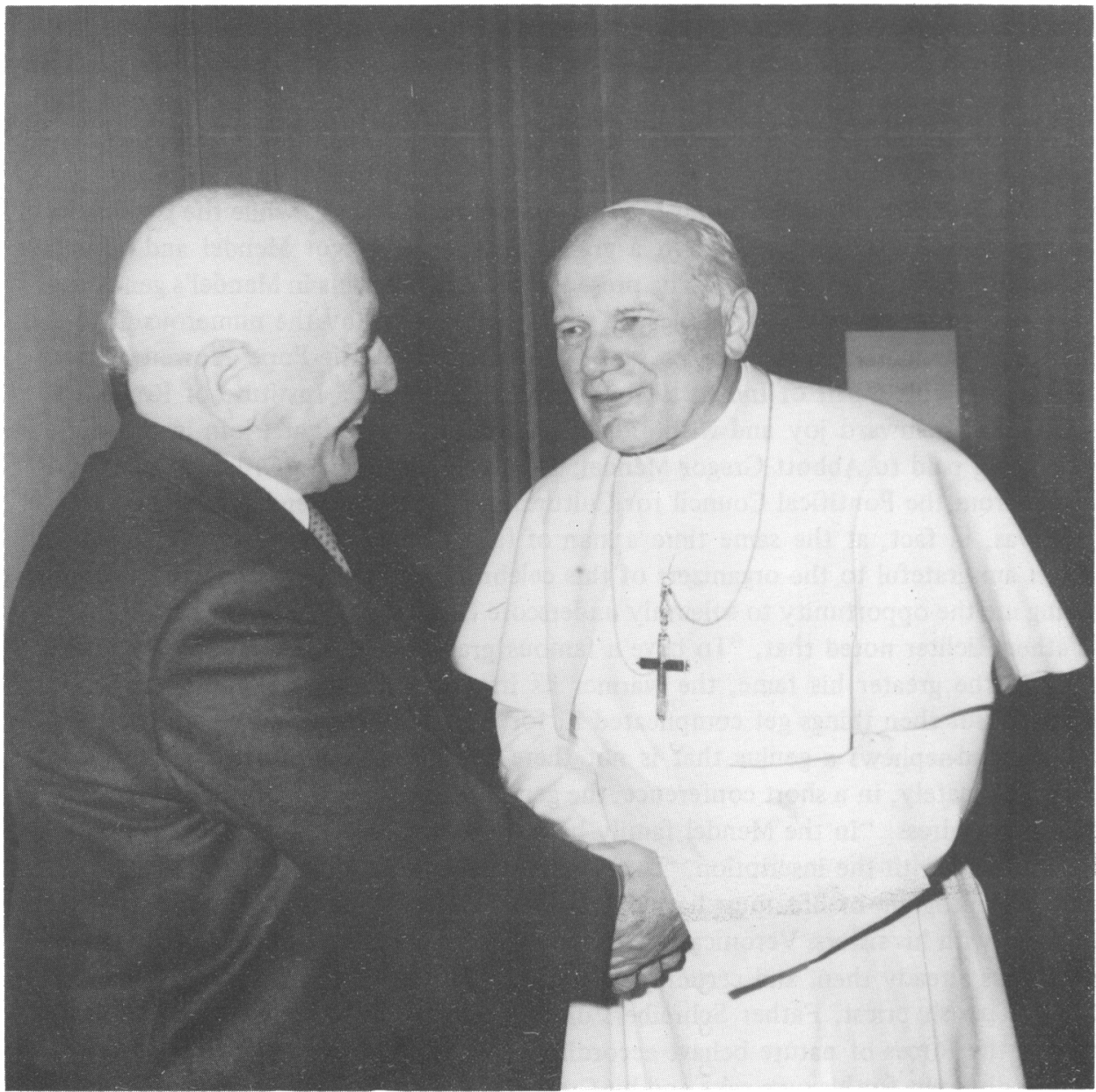

Fig. 2 - The Pope expressing his appreciation to Professor Gedda over the activity of the Mendel Institute on the occasion of the celebration of the Centennial of Gregor Mendel's death. 


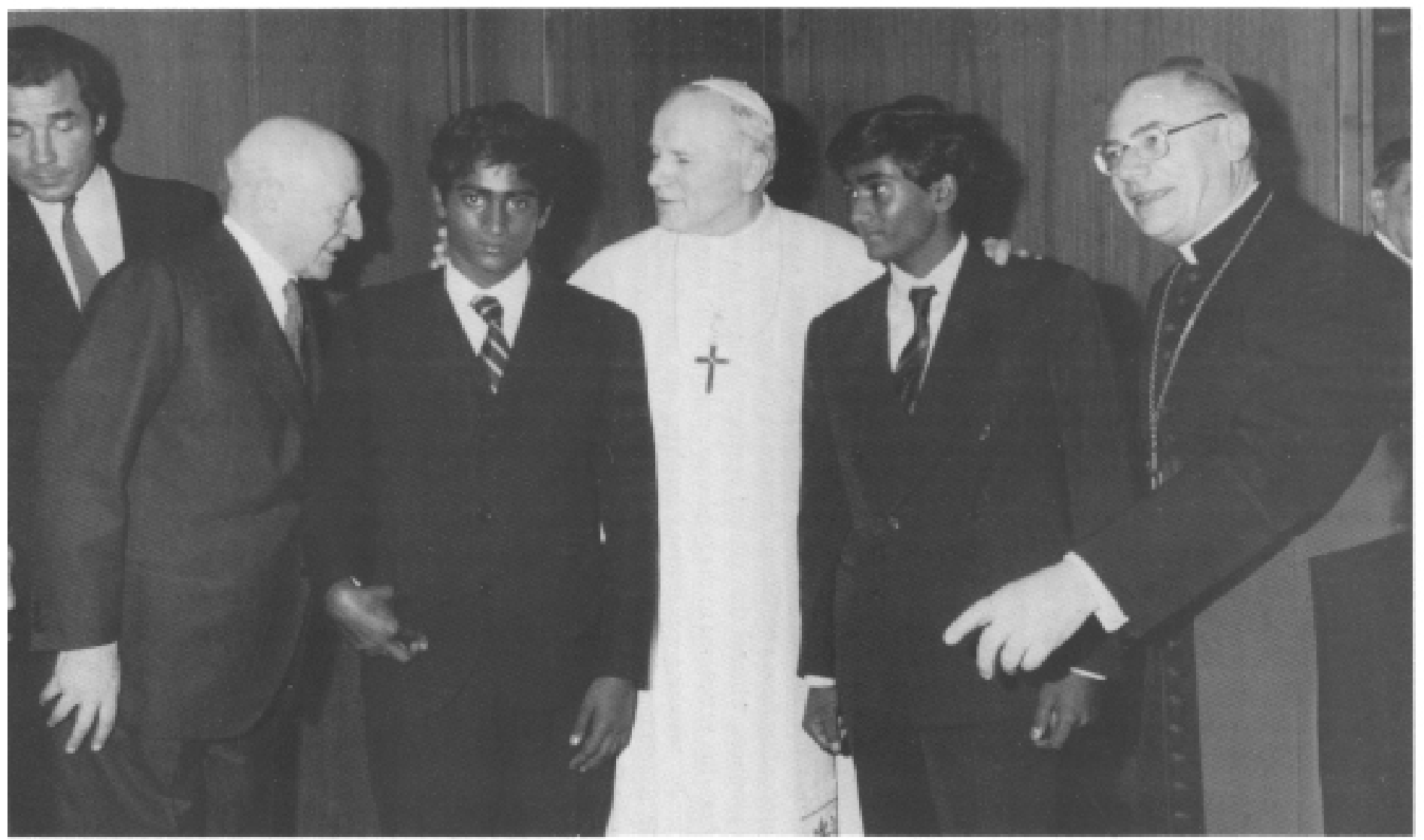

Fig. 3- The Pope with two Indian twinx folowed by the Mendel Iestatute en the ocession of the celebration of the Centennial of Gregor Mendel's death 
In my turn, I have referred to twin research and chronogenetics with these words: "From the 1950s to the present time, genetics has spread out in all areas of medicine and the analysis of the basic hereditary unit discovered by Mendel has come to acquire a fourth dimension, the temporal one. It is thanks to twins that this has happened, thanks to the simple and common observation that the twins derived from one and the same fertilized egg are identical, so identical as to be mixed up. What surprises in the fact that this identicalness is not superficial and occasional, as it happens with doubles, but applies to the molecular level, and evolves simultaneously in the course of ontogenesis and even later on, when the twins live in the same environment. That means that the battery of genes responsible for development proceeds synchronously in the two twins; that is, each of the some 70,000 genes of the human genome has a lifespan that is genetically set. This also means that when the gene mutates and stops producing its information, it causes the corresponding hereditary disease, which in fact appears at the same time in monozygotic twins. This also means, finally, that the gene possesses a chemical and physical stability responsible for its own time of action. The 'time parameter' of the gene, that we have called 'chronon,' is the object of study of Chronogenetics".

The Holy Father John Paul the Second again took part in Mendelian celebrations at Viterbo, where the School of Agriculture led by Professor Scarascia Mugnozza dedicated the University's main hall to Gregor Mendel. I also took part in that meeting and gave a presentation entitled, "From Medical Genetics to Clinical Genetics". I noted, on that occasion, that the medical geneticist follows a systematic approach to the hereditary disease, proceeding from a mutational damage to the hereditary make up to the symptoms that this produces, whereas the clinical geneticist follows the opposite mental itinerary, moving from the symptoms to the syndrome, and from the latter to its repeated presence in the family, searching connections involving age and the specific environment, and eventually concluding for the presence of a hereditary component, since a 'Mendelian truth' can be found in any clinical manifestation.

Mendel's Centennial was also celebrated at the University of Paris-Sud (Centre Scientifique d'Orsay) with a European Colloquium on the subject of "Man and the Aims of Genetics". Brenci and I took part with a presentation on "The Temporal Dimension of Information", in which we described our "Twins Living Apart Test" and our study of pairs who had been living apart for at least five years as a result of marriage, which indicated environmental factors to influence height and weight, presbyopia, presbyacusia, blood pressure, dental caries, sleep, etc. This indicates that Mendel's "hereditary factors" exhibit a different physical and chemical stability according to the environment in which they operate.

Finally, in Rome again, at the "Center of Comparison and Synthesis", I stressed the importance of Mendel's discoveries for the identikit of man, since the individual genome is unrepeatable and confers an objective individuality to each human being (considering that gene-environment interactions can also differentiate monozygotic cotwins). I particularly underscored the genetic relation between parents and children, which represents a fundamental aspect in the rearing up process, as well as the phenomena related to affectivity and the unconscious, as the reared apart twin studies also have demonstrated.

From The Mendel Institute

Luigi Gedda November 1984 